\title{
Thoughts on Cultural Consciousness, Self-confidence and Ethnomusicology Research Status
}

\author{
Yi Ji \\ Music and Dance College \\ Qujing Normal University \\ Qujing, Yunnan, China 655011
}

\begin{abstract}
The party's 18th CPC National Congress proposed that we must establish a high degree of cultural awareness and cultural self-confidence, cultural awareness and cultural selfconfidence based on the research of music acts and cultural issues are the core of ethnomusicology research. In this article takes the musical acts and cultural consciousness, self-confidence as study objects, explored their current situation and trends, pointed out the lack of academic research on the dimensions, contents, methods; and discusses the study objectives and value, it believes that cultural consciousness and cultural selfconfidence is the cultural value appearance based on the core values of the socialist cultural values. Promoting cultural awareness and cultural self-confidence of ethnomusicology research has become a major practical problem to be solved in cultural construction in China.
\end{abstract}

Keywords-cultural consciousness; cultural self-confidence; ethnomusicology; current situation; value; target

\section{INTRODUCTION}

Since the 21st century, especially after the party's 18th CPC National Congress proposed that we must establish a high degree of cultural awareness and cultural self-confidence, the country's central and local governments continue to increase investment for cultural software and hardware construction ,increase cultural projects, expand the scope of culture, actively improve cultural level, a big cultural value system which covers urban and rural residents is shaping, national cultural soft power is significantly promoted. In the meanwhile of expanding the universality of cultural construction, but also produces the separation between cultural events especially music acts and socialist core values, the separation between urban and rural cultural values, the "Fragmentation" phenomenon about Folk music Cultural Values and so on. On the other hand, anthropology theory study with a clear academic core idea is developing rapidly in China, especially the deep study in the minority nation music and religious music themed research, it accumulate experience date for the theory practice of Chinese Ethnomusicology. But it is lack of specific and detailed research which from the macro, meso and micro views is integrated to gather musical acts and cultural issues to explain the specific orientation, operational mechanism and construction of cultural values. Music act is a special and significant cultural phenomenon, cultural awareness and cultural self-confidence is a cultural

This article is the research result for the college project from Qujing Normal University, "anthropological study on music cultural awareness and cultural self-confidence - Take Yunnan Province as a study case" project number: 2013QN023. values appearance based on the socialist core values. Promoting cultural awareness and cultural self-confidence of ethnomusicology research has become a major practical problem to be solved in cultural construction in China.

\section{REVIEW OF THE CURRENT SITUATION AND TRENDS FOR THE DOMESTIC AND ABROAD RESEARCH}

\section{A. Domestic Research}

In recent years, cultural issues and ethnomusicology research have attracted the attention of domestic music circles, some scholars and research institutions made some exploratory research, existing results mainly include following three aspects: 1 . The urgency and importance of our cultural issues and ethnomusicology research. Guan Jianhua and others has explained the definition of ethnomusicology, traces the history of ethnomusicology, discusses the blending relationship between music and social cultural structure and the use theoretical philosophy, anthropology, psychology and other disciplines conducted in-depth research and commentary to today's global music culture ; at the same time, raised the issue of discourse relations and cultural exchanges between Chinese and Western music and the music communication mode in cultural criticism post-colonial era and higher music education issue; he proposed new cultural integration and build issues; and Chinese music and Western music truly fair dialogue, criticism, positive positioning issues. It discusses the urgency and necessity of Chinese cultural issues and the ethnomusicology research. Guan Jianhua said: "Cultural Studies through traditional, modern, postmodern, from the center to the edge, from the edge to the center, its purpose is to require dialogue", "The biggest problem of Chinese music is it does not form a truly fair dialogue in culture with the Western Music, the real criticism and the real recognition." "The relationship between 'main cultural identity' and 'dominant position and circumstances' in Post-colonial Context, it decides the music and cultural communication positioning issue." 2 . Our cultural issues and specific content of ethnomusicology research. Guan Jianhua, Luo Qin and others discusses the cultural issues and the meaning, principle, process and method for ethnomusicology research, and elaborates on the meaning, goal, method and key point for ethnomusicology research. 3 . The basic ideas and system integration of music and cultural issues and ethnomusicology research. Shanghai Institute of Ethnomusicology E- College established in 2005 believes that 
music studies not only for the music itself, and should include musicians' behavior related with social and cultural environment. It believes under the influence of Ethnomusicology, function and role of the music is under an unprecedented transformation. Future prospects and musicology of music no longer mainly with specific or narrow forms, especially not mainly with the study of Western classical music, it will take all humanity musical and cultural backgrounds as its range, take the study of people, social and culture as its purpose and meaning. Ethnomusicology has become the leading subject in music research fields and it is changing people's awareness and understanding to the music. E- College takes this academic philosophy as its general plan for the discipline construction.

\section{B. Foreign Research}

Literature search showed that foreign scholars have little research about our cultural issues and Ethnomusicology in our country, but they made some music culture theory of cultural consciousness and music anthropology confidence which has important reference value. Mainly it includes five aspects: 1 Merriam "ethnomusicology" proposed to bring all human social culture into their study. Cross-cultural studies Ethnomusicology 2.Since 70s of 20th century, the intercultural Ethnomusicology study has pointed out the status of the similarities and comparative study. In 1992, former President of the US Music and National Society JM Slobin has brought the global culture classification concept of "super-culture, subculture, interactive culture" as an expression of how to get new understanding and awareness for local music culture and global music culture concept base on the new environment. 3 . Cultural anthropology study under music transition. Theory of global music transition is proposed by Lomax and deeply developed by Brian gold Nettle. Nettle presents 10 ways for music and Cultural transition: (1) tradition exhausted; (2)tradition preservation; (3) diversification; (4) strengthen unity; (5) reintroduction; (6) exaggeration; (7) ironic; (8) integration; (9)Westernized; (10) modernization. 4. Study of structuralism Ethnomusicology. "Theme" and "Class", "I" and "otherness" which introduced from linguistics have become two important dimensions for today's Western music study. 5. Study of applied Ethnomusicology. The relationship between intercultural and music communications, the common trend of ethnomusicology and music education become international research priorities.

In summary: During the process of researching our cultural issues and Ethnomusicology, the academic experts have proposed a number of valuable and enlightening ideas, but there are obvious shortcomings: First, depth and comprehensive of research dimension are not enough. Some perspective from folk music, some from religious music, but most researchers have not yet to break through the concept of musical cultural values, lack of macroscopic visual threshold of musical cultural value; Second the research is not comprehensive, in the integration of our musical culture and society, there were some major issues such as the current situation and trends, theoretical foundation and operation mechanism and standards and strategies, the research for the above issues are not enough; Third, the research method empirical is not strong, existing work result has a relatively strong feature of "ought to be", "conception "and" normalization ". We need to further enhance the empirical fieldwork research. These deficiencies indicate that our cultural issues and Ethnomusicology research is still a problem not fully solved, it is necessary to conduct fully and deeply Ethnomusicology research about cultural awareness and cultural self-confidence.

\section{THOUGHTS ABOUT THE GOALS AND VALUES FOR Cultural CONSCIOUSNESS, SELF-CONFIDENCE AND ETHNOMUSICOLOGY RESEARCH}

\section{A. Goals}

I believe that the research goals for cultural consciousness, confidence and ethnomusicology research are the following main points: 1. Through exploring research results in and abroad about cultural issues and ethnomusicology, to further explain the concept,emergence and development of musical culture in order to make deeper and better understanding about current situation of this particular musical culture research which is cultural awareness and cultural self-confidence in Music behavior, and the goal is to think this particular existing mode. In addition, through choosing holistic phenomena of musical culture and behavior explanation in Frontier Ethnic Regions as an object to provide a high-level overview theoretical explain framework. 2. During music acts, choose individual level cultural interaction phenomena among Ethnic Frontier Regions and problems interpretation as the object to conduct individual micro-inspection, to provide a paradigm for reference. Furthermore, through explaining the position and application for cultural awareness and cultural self-confidence in music behavior, to make further explore of the theory foundation of cultural awareness and cultural self-confidence and make further explanation about its operation mechanism. 3 . The research which with the theme of cultural awareness and cultural self-confidence chose China's Border Region as specific cases, through examining their personal, ethnic music and cultural values, comparative analysis of how their music achieved to be guided by their own cultural values and Music Ideas, and then tried to explain the process of music and how does individuals and communities achieve cultural awareness and cultural self-confidence? And trying to strengthen the mutual relationship between "main cultural identity" and "the dominant position and situation", revealed "common" and "personality" features for personal and group music activities in order to enrich the connotation of music theory and promote the development of ethnomusicology research.

\section{B. Values}

I believe that value of the cultural consciousness, selfconfidence and the ethnomusicology research is mainly reflected in theoretical and practical application two aspects. Theoretical value are as follows: 1. The party's 18th CPC National Congress proposed that we must establish a high degree of cultural awareness and cultural self-confidence, according to the practical problems to be solved for Chinese ethnomusicology research, we can choose the Border Minority Areas for the study object. Reflect the necessity, feasibility, 
scientific and innovative of research. 2. Music behavior is a special and significant cultural phenomenon, and cultural awareness and cultural self-confidence reflect the core cultural values. Researchers clarify the relationship between the overall music behavior of the Ethnic Frontier Regions and cultural awareness and cultural self-confidence through the ethnomusicology research methods, combining cultural anthropology, folklore research methods to make deeply analysis for cultural awareness and cultural self-confidence phenomena and mode which revealed by music behavior. The analysis expanded understandings for human musical behavior, social and general cultural, helped enrich people's awareness and focus on cultural self-confidence and cultural consciousness acts during music activities. The analysis established academic status of music cultural studies, thus promoted the theory and practice of cultural consciousness and cultural self-confidence, and further enriched and developed the theory of ethnomusicology. 3. Through Music Behavior to study the current situation of cultural consciousness and cultural self-confident in Ethnic Frontier Regions, explore the emergence and development of cultural self-confidence and cultural consciousness, and help enhance the cultural creativity of the whole nation. Analysis of individual and group music behavior and combing cultural awareness, self-confidence theory in order to get the particularity and universality with cultural awareness and cultural self-confidence existing mode during music acts. And the discovery of its theoretical value and enlightenment of Musical Culture Study can guide music practice, verify the real value and theory meaning of cultural consciousness and self-confidence in ethnomusicology research. 4. Music behavior and cultural awareness and cultural self-confidence influence and compromise with each other. Through detailed analysis of this interaction, we can get the individuality and generality understanding of the music culture process and the law of value. Practical applications include: 1. The goal of Cultural Awareness, cultural selfconfidence and ethnomusicology research is to use ethnomusicology research methods to analyze the particularity and universality in the music cultural awareness and cultural self-confidence during music behavior, and to analyze the emergence and existence premise, generation and development power, and reveals its essential nature, get the individuality and generality understanding of the music culture process and the law of value.

Study not only can enhance the connotation of Ethnomusicology, accumulate empirical data, but also it can explain the value and meaning for cultural value orientation in a multicultural theory. In addition, it has important policy recommendation value for protecting and heritage the folk music culture which based on cultural consciousness and selfconfidence. 2. From the cultural awareness and cultural selfconfidence appearance of individual and group, we can make comparative analysis and can explain how to achieve their cultural awareness and cultural self-confidence under the guidance of their behavior and cultural values? What are the differences between individuals and groups about the conscious and value of cultural self-confidence and cultural awareness? And reveal the "common" and "personality" to reveal the relationship between music acts and cultural awareness and cultural self-confidence. This will help promote the value orientation of the Chinese music culture, and strengthen the relationship between "subject of cultural identity" and "dominant position and situation" .This has important policy reference and work guiding value for promoting cultural exchanges between Chinese and Western musical discourse relations, and also cultural criticism postcolonial era and Music Exchange mode and higher music education research. 3. There is no direct study of cultural awareness and cultural self-confidence in China's Ethnomusicology research. The researchers' study can inspire more scholars to make more deeply theoretically explorations in this area in order to promote the development of Chinese Ethnomusicology.

\section{CONCLUSION}

Researchers should note the following two aspects: on one hand, our cultural issues and ethnomusicology research are still not fully resolved problems, academic research has deficiencies in dimension, content and methodology, and the study goal and value need to be deepened. On the other hand, cultural awareness and cultural self-confidence is a manifestation of cultural values based on socialist core values, cultural awareness, self-confidence and ethnomusicology studies should based on the perspective of ethnomusicology, study the connotation of cultural awareness and cultural selfconfidence, explore theoretical basis of cultural issues and ethnomusicology research, and then to conduct a comprehensive in-depth study of ethnomusicology about cultural awareness and cultural self-confidence.

\section{REFERENCES}

[1] Guan Jianhua. Cultural Studies and Ethnomusicology [J]. Chinese music, 2001 (2).

[2] Guan Jianhua, Luo Qin View of Ethnomusicology: music study from global cultural vision. [M] Shanghai Conservatory of Music Publishing, 2010.

[3] Merriam, Mu Qian Ethnomusicology [M] Beijing: People's Music Publishing House, 2010.

[4] Slobin, Chen Mingdao Global music culture and subculture problem [J] Chinese music, 1995, Suppl.

[5] Lomax, Zhang Weihua Called for the culture equality [J]. Music Studies and Research, 1988, (4).

[6] Kuang Hui, Cao Feng. Important contribution of basic ideas of cultural anthropology to modern European music education and cultural development [J]. Chinese music, 2001, (4).

[7] Liu Yonglian Music Education under Ethnomusicology Perspectivestudy of John. Blacking's thought [M] Hefei: Anhui Normal University Press, 2010. 